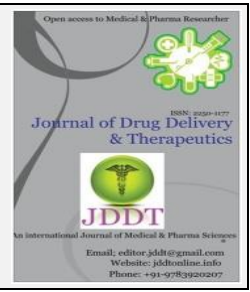

Open $\odot$ Access

Review Article

\title{
Contract Research Organization (CRO): An Important Partner to Biotechnological and Pharmaceutical Companies
}

\author{
R. Santosh Kumar* and Sangbit Paul \\ GITAM Institute of Pharmacy, GITAM (Deemed To Be University) Rushikonda, Visakhapatnam-530045, Andhra Pradesh, India.
}

\begin{abstract}
With the ever increasing Research and Development cost for the pharmaceutical industries, the cost of bringing a drug to market was increasing drastically. The funds for drug development was drying up and thus to maintain a healthy profit margin , the pharmaceutical companies have adopted to frame out research and development (R\&D) to Contract Research Organizations (CRO's). The CRO's have become an important partner to biotechnological and pharmaceutical companies, in the development of new compounds and at the same time in drug registration also it has extended its hands. Out of 20,19 pharmaceutical companies have invested in emerging markets like China, India, Russia and Latin America since clinical research is accessible to these markets due to adoption of ICH and GCPs guidelines. The traditional nature of CRO's have changed and they will develop into a formidable industry in near future.
\end{abstract}

Article Info: Received 08 July 2019; Review Completed 12 Aug 2019; Accepted 20 Aug 2019; Available online 30 Aug 2019

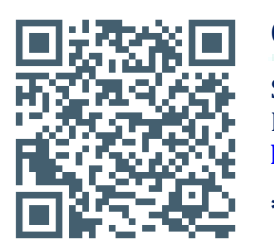

Cite this article as:

Santosh Kumar R, Paul S, Contract Research Organization (CRO): An Important Partner to Biotechnological and Pharmaceutical Companies, Journal of Drug Delivery and Therapeutics. 2019; 9(4-A):759-761

http://dx.doi.org/10.22270/jddt.v9i4-A.3481

Address for Correspondence:

INDIA.

\section{INTRODUCTION}

In the late 1970 to early 1980s the Research and Development (R\&D) cost for the pharmaceutical industries were increasing drastically. R\&D cost has been doubling every 5 years for the pharmaceutical industries since 1970; in 1989 the average cost of bringing a drug to market was $\$ 125$ million and climbed to $\$ 231$ million in 1993.[1] Since 1980 the prescription drug prices have increased at an average rate of 2.3 times faster than that of consumer prices, [2] the probability of developing a new drug was very less. According to the center for study of drug development at tuft's university, if every 5000 compounds that are synthesized, just 5 will enter the clinical trials out of which one will be approved by the FDA. Since the R\&D costs were increasing, thus the concept of CRO came to limelight, which helped the pharmaceutical \& biotechnological industries.

\section{INDUSTRY BACKGROUND}

Pressure on the pharmaceutical industry from the early 1990s

For the high risk biotechnology product, the fund from drug development was drying up. In 1991, $\$ 6.5$ billion was raised by biotech companies; however in 1992,just $\$ 5$ billion was raised. A loss of $\$ 1.4$ billion was suffered as the industries stock fell $6 \%$ to $\$ 45$ billion, while R\&D expense rose $14 \%$ to $\$ 5.7$ billion.[3]

1. Pricing pressure : With the increase in drug prices, the public become discontent with the cost of drugs, hospitalization increases. During the course of time when the generic drugs flows in the market, the pharmaceutical company have to give a wake up call. Then the Health Maintainance Organizations (HMOs) was constructed which demands price cuts from the drug companies. Congressman Henry Waxman stated, “ If we are serious about controlling health-care costs,we must address the issue of prescription drug prices. Congress, as part of health reform, must find a way to balance profits and prices in a way fairer to the American consumer." [4]

2. R\&D Cost Increases Faster Than Price : The pharmaceutical industries continued spending on R\&D, despite of pricing pressure. In 1993 on R\&D the top 30 companies spent $\$ 20$ billions, representing $18.3 \%$ of sales while in 1994 there was a slight hike by $\$ 6$ billion only. [5] 


\section{ALTERNATE APPROACHES TO PHARMACEUTICAL RESEARCH AND DEVELOPMENT}

To respond to the pressure and to maintain a healthy profit margin, the pharmaceutical companies have adopted various approaches:

1. Downsizing and early retirement: To reduce workforce, many companies offered early retirements.

2. Out-licensing non-major products.

3. Merge and consolidation: To expand their product lines, pharmaceutical companies merged. Some of the companies that merged at that time were SKF and Beecham, Merck and Johnson and Johnson Joint venture, AHP and American cyanamide.

4. Co-marketing : To expand market share, the sales force of different companies were merging. For example, Smith Kline Beecham and DuPont comarketed SKB's Tagamet.

5. Potential major market share drugs were developed.

6. Developing one's own generic business: Separate generic house was established to compete with manufacturers of generic drugs.

7. An OTC market was developed that was not under the price limit.

8. To grow market share price cut was adopted.

9. Giving up research.

10. Farming out R\&D to CRO's: The CRO unit was used as an independent quality control hand.

\section{EMERGENCY OF THE CONTRACT RESEARCH ORGANIZATION INDUSTRY}

\section{Contract Research Organization in the Public Market}

As the R\&D Cost increases, pressure from the health care reform forced pharmaceutical companies to staff at trough and to use CRO's to supply their needs.

\section{Growth of the contract research organization industry}

Increase of outsourcing by Pharmaceutical and Biotechnology companies

At the end of 1997, the pharmaceutical and biotechnology companies expenditure on R\&D exceeded $\$ 35$ billion, out of which $2 / 3$ is attributed to clinical research. Approximately $\$ 2.5$ billion was awarded to the CRO industry, and is expected to grow $10 \%$ a year.

Full service contract research organizations grow rapidly

Due to the following reasons, full service CRO's are growing rapidly :

1. The motivation for drug firms to outsource clinical testing.

2. The biotechnology research expansion.

3. For medical device manufacturer, the greater clinical testing requirements were made mandatory.

4. Due to industry consolidation which results in market share gains.

5. The rewards given on the first product to market.
Finally the pharmaceutical companies started to recognize the advantage of developing deep relationship with a limited number of vendors. CRO's able to service the full continuum of R\&D which needs the following capabilities:

1. For designing clinical trial a broad range of therapeutic expertise.

2. To collect, analyze and manipulate data aCRO'ss many geographically dispersed sites from many patients with various clinical conditions.

3. A full range of trial management services is provided to customers who wish to narrow their relationships to a limited number of CRO's for drug development activities.

4. To conduct trials and allowing simultaneously filling of registration packages in several major jurisdictions.[6]

Upstream and Downstream Growth of Contract Research Organizations

More than 200 Drug Information Association (DIA) registered CRO'S was established by the end of 1994 in the United States $[7,8]$ and a similar number of CRO was there in western Europe. To attract pharmaceutical clients ,the CRO's started giving wider range of services as an important incentive. Starting in 1996, large CRO's brought contract sales service organizations. "Although there have been moves to harmonize product registration and requirements, nevertheless, it is still a multidomestic market with different medical rules, regulations, laws, and medical practices in every country." Companies that are specialized in combinatorial chemistry and functional genomics, there the CRO's started spending more.

Future of the Contract Research Organization Industry in the Pacific Rim.

\section{Market size for Pharmaceuticals}

The Japanese pharmaceutical market is about $20 \%$ of the world market, with an annual growth rate of $10 \%$ "Thus recently, the need for CRO's in Japan was recognized." [9] The need of CRO's in Japan was given in a study group (Honma Group) by the Ministry of Health, Labor and Welfare. Various multinational CRO's established small CRO's groups. The need for CRO's was observed in Australia, south east Asia, India/ Pakistan, Eastern Europe, and latin America.

\section{Critical issues to ensure the quality of clinical trials}

To ensure the quality of clinical trials, the critical issues that include are as follows:

1. The attitude of medical professionals: Medical professionals in most pacific rim countries (except China) enjoys a special social status. The CRO monitors have to deal with the harsh behavior of the medical practitioners. A high percentage of errors are generated in case reports with this type of attitude of the investigators.

2. Informed consent: Clinical research cannot be done without the proper protection of the rights of the patients, which will require a great effort to educate both the investigators and patients. The language of the informed consent form should be simple and understandable by the participants of the trial.

3. Transparency of budgeting and payment: Each budget item should be clear, accountable and must reflect the needs of the local trial. 
4. Respect for intellectual property: This will act as an encouragement for the multinational companies to conduct more trials in that specific region.

5. Time availability of the investigators and coordinators: Some investigators have very limited time to do research.

6. Simplifications of the governmental approval process: There should be an independent relationship between the sponsors and the governmental officials regarding the approval process. The approval process should be clear in turn to the general public.

7. Affordable central laboratories: Clinical data from Asia will be a part of the multinational submission in the near future.

\section{EXTENSION OF TRADITIONAL CONTRACT RESEARCH ORGANIZATION SERVICES}

Traditionally $\mathrm{R} \& \mathrm{D}$, sales and marketing were generally treated as the core value and as proprietary by the pharmaceutical and biotechnology companies. In 1997, there was a major shift in the FDA policy towards direct marketing by pharmaceutical companies to the potential consumer was announced. This policy shift in turn opens the window for CRO's to provide contract sales service to pharmaceuticals and biotechnology companies.

Since the site management organization have started to grow in number, to consolidate the experience of mixing CRO's and SMOs has not been very impressive. CRO's that provide the technology to enhance integrated information processing, real time status, information sharing and global data harmonization are taking the lead in the market. The IT services in this field will grow but the success rate is usually low.

\section{CONCLUSION}

In the development of new compounds, the CRO's have become an important partner to biotechnological and pharmaceutical companies. In drug registration also CRO have provided its hands. The pharmaceutical and biotechnology companies spend on $\mathrm{R} \& \mathrm{D}$ is estimated to exceed $\$ 35$ billion. Out of which $2 / 3$ rd is spent on clinical trials and CRO have captured only $10 \%$. 19 out of 20 pharmaceutical companies have invested in emerging markets like China, India, Russia and Latin America .Clinical research is accessible to these markets because of fast enrollment of patients because of the improvement in adopting the practice of the ICH and GCPs. In the next 10 years, the Asia market for CRO's will expand rapidly. The CRO has acquired marketing and sales capabilities to extend services down streams. The estimate of worldwide R\&D spending is somewhat close to worldwide marketing and sales expenses. The growth and consolidation of CSOs will be accelerated, if the growth of the traditional CRO's is any indication of the potential growth of CSOs. From other industries larger players will protrude to capture the growth. The nature of traditional CRO's has changed, and they will evolve into a formidable industry in the near future.

\section{REFERENCES}

1. Thomas, S. Insight $1996,4,11-14$

2. Sperry, P. Investor's Business Daily; August 24,1993

3. T.Y. Lee, ScD, Contract Research Organizations, Drug Information Journal,1998;32(1):1259S-1263S

4. The Star Ledger; February 3,1994

5. Otto Andersen, Internationalization and Market Entry Mode: A Review of Theories and Conceptual Frameworks, MIR: Management International Review,1997;37:27-42

6. J.C.Bradford and Co., Healthcare Service Basic Report;1998

7. Drug Information Association. Pharmaceutical Contract Support Organization, 1994

8. Center Watch Weekly March 9,1998,1, (30).

9. Bentley , S. Clinical Research and CRO's in Japan. Appl.Clin.Trials April 1997,1,30-34. 